\title{
Sex ratios among Canadian liveborn infants of mothers from different countries
}

\author{
Joel G. Ray MD MSc, David A. Henry MBChB, Marcelo L. Urquia PhD
}

Competing interests: None declared.

This article has been peer reviewed.

Correspondence to: Dr. Joel G. Ray, rayj@smh.ca

CMAJ 2012. DOI:10.1503 /cmaj.120165

\begin{abstract}
Background: There has been much discussion about whether female feticide occurs in certain immigrant groups in Canada. We examined data on live births in Ontario and compared sex ratios in different groups according to the mother's country or region of birth and parity.
\end{abstract}

Methods: We completed a population-based study of 766688 singleton live births between 2002 and 2007. We used birth records provided by Ontario Vital Statistics for live births in the province between 23 and 41 weeks' gestation. We categorized each newborn according to the mother's country or region of birth, namely Canada ( $n=486599$ ), Europe $(n=58505)$, South Korea $(n=3663)$, China ( $n$ $=23$ 818), Philippines ( $n=15367)$, rest of East Asia $(n=18971)$, Pakistan $(n=18018)$, India ( $n=31$ 978), rest of South Asia $(n=20695)$ and other countries $(n=89074)$. We calculated male:female ratios and $95 \%$ confidence intervals $(\mathrm{Cls})$ for all live births by these re- lthough there are some myths about correctly guessing the sex of a fetus, ${ }^{1}$ modern-day prenatal ultrasound enables the identification of whether a fetus is a boy or girl with $99 \%$ accuracy. ${ }^{2}$ There has been much discussion about whether female fetuses are at higher risk of pregnancy termination than male fetuses in certain ethnic groups. In India, a study of data from the National Family Health Survey for 265516 births showed a sharp in crease in the male:female ratio among secondorder births when the firstborn was a girl, and no significant increase when the firstborn was a boy. ${ }^{3}$ The authors attributed this trend to the practice of selective abortion of female fetuses. A recent editorial ${ }^{4}$ and news item ${ }^{5}$ in $C M A J$ suggested that female feticide may also be occurring in Canada. ${ }^{6}$ Rather than using live-birth statistics, the Canadian study cited in CMAJ used data from the 2001 and 2006 Canada Census long-form questionnaires, which were completed by $20 \%$ of the population and relied on self-reporting of additional information, includ- gions and stratified them by maternal parity at the time of delivery $(0,1,2$ or $\geq 3)$.

Results: Among infants of nulliparous women, the male:female ratio was about 1.05 overall. As parity increased, the ratio remained unchanged among infants of Canadian-born women. In contrast, the male:female ratio was significantly higher among infants of primiparous women born in South Korea (1.20, 95\% Cl 1.09-1.34) and India (1.11, 95\% Cl 1.07-1.15) than among infants of Canadian-born primiparous women. Among multiparous women, those born in India were significantly more likely than Canadian-born women to have a male infant (parity 2 , ratio $1.36,95 \% \mathrm{Cl} 1.27$ 1.46 ; parity $\geq 3$, ratio $1.25,95 \% \mathrm{Cl} 1.09-1.43$ ).

Interpretation: Our study of male:female ratios in Ontario showed that multiparous women born in India were significantly more likely than multiparous women born in Canada to have a male infant.

ing the number of family members in a given household.

We used contemporary data on live births in Ontario, Canada's most populous and ethnically diverse province, and compared sex ratios among infants of Canadian-born women with sex ratios in different immigrant groups. We focused on immigrant groups from countries purported to have the highest rates of preference for a son following the birth of one or more daughters. ${ }^{3-6}$ We determined whether the male:female ratio increased with increasing parity in certain immigrant groups, as has been previously suggested. ${ }^{3,6}$

\section{Methods}

We evaluated all singleton live births in Ontario between 2002 and 2007 using birth records provided by Ontario Vital Statistics. We included births between 23 and 41 weeks' gestation. The birth record requires the submission of two documents: one from the attendant or certifier (i.e., 
physician or midwife) and the other from a parent. Also included in the parent's submission is maternal age at delivery, parity, marital status of the parents (married, not married or not stated) and birthplace of the infant's mother and father.

We categorized each newborn according to the mother's country or region of birth, namely Canada $(n=486599)$, Europe $(n=58505)$, South Korea $(n=3663)$, China $(n=23$ 818), Philippines $(n=15367)$, rest of East Asia $(n=18971)$, Pakistan $(n=18018)$, India $(n=31978)$, rest of South Asia $(n=20695)$ and "other" $(n=89074)$. We calculated male:female ratios for all live births by these regions and stratified them by maternal parity at the time of delivery $(0,1,2$ or $\geq 3)$.

Infants of women born in Canada formed the comparison group. Some countries were chosen because the sex ratio of family households in those countries may favour boys (India and South Korea). ${ }^{3,6}$ Others were chosen because they neighbour those countries (Pakistan and China). The remaining countries and regions represent origins of large immigrant groups to Ontario. More than one birth may have been included in the study for a given woman, and sequential births could not be linked to the same woman or sibling.

In a sensitivity analysis, we recategorized each newborn according to couples with the same county of birth, as listed above, again stratifying by parity.

All data were de-identified before receipt, and permission to complete the study was obtained from the Research Ethics Board of St. Michael's Hospital, Toronto, Ontario.

\section{Statistical analysis}

The binomial proportions of males $\left(\mathrm{P}_{\text {males }}\right)$ and their $95 \%$ confidence intervals (CIs) were used to calculate the male:female ratios based on the formula: $\mathrm{P}_{\text {males }} /\left(1-\mathrm{P}_{\text {males }}\right)$. Sex ratios and $95 \%$ CIs were plotted graphically by maternal country of birth and parity, with a natural ratio of 1.05 serving as the baseline.

\section{Results}

We included 766688 singleton live births in the study (Table 1). About $64 \%$ of the mothers were born in Canada, 4\% in India, 3\% in China and $2 \%$ in Pakistan. The proportion of mothers with a parity of three or more was highest in Pakistan and "other" countries (Table 1). The proportion of newborns whose father was born in the same country as the mother was about $90 \%$ for newborns whose mother was born in Pakistan or India, 83\% for mothers born in China and about $70 \%$ for mothers born in South Korea or Canada.

Based on the mother's country of birth, the male:female ratio among nulliparous women was about 1.05 for all countries except China, where it was nonsignificantly higher $(1.09,95 \%$ CI 1.05 1.13) (Figure 1). As parity increased, the male: female ratio remained unchanged for infants of Canadian-born mothers. In contrast, the ratio was significantly higher among infants of primiparous women born in South Korea (1.20, 95\% CI 1.091.34) and India (1.11, 95\% CI 1.07-1.15) than among infants of Canadian-born primiparous women. Among multiparous women, those born in India were significantly more likely than Canadian-born women to have a male infant (parity 2, ratio $1.36,95 \%$ CI $1.27-1.46$; parity $\geq 3$, ratio $1.25,95 \%$ CI 1.09-1.43) (Figure 1).

When we limited the analysis to infants whose parents had the same country of birth, the male:female ratios were essentially unchanged, although they were slightly higher among infants of multiparous women born in India (Appendix 1, available at www.cmaj.ca/lookup/suppl /doi:10.1503/cmaj.120165/-/DC1).

\section{Interpretation}

After reviewing all registered singleton live births in Ontario between 2002 and 2007, we found a significantly higher male:female ratio among infants of multiparous woman originally born in India than among infants of multiparous women born in Canada. The only other women more likely than their Canadian-born counterparts to give birth to a male infant were primiparous women from South Korea.

Our findings raise the possibility that couples originating from India may be more likely than Canadian-born couples to use prenatal sex determination and terminate a second or subsequent pregnancy if the fetus is female. Our inability to determine the birth order of male and female infants born to multiparous women in our data set would be expected to dilute our observed effect sizes, because some women who initially had one or two consecutive sons might be less inclined to terminate a subsequent pregnancy with a female fetus. ${ }^{3}$

Prior research conducted in India observed an association between increasing male:female ratios and increasing parity. ${ }^{3}$ Specifically, the male:female ratio in 2005 was 1.20 if the previous living child was female, and 1.30 if the previous two were female; no effect was seen when one or more previous children were male. ${ }^{3} \mathrm{~A}$ prior study using Canadian census data for South Asian and East Asian immigrants reported a male:female ratio of 1.05 at first parity, regardless of ethnic background. ${ }^{6}$ The sex ratio for third births when the previous two children were fe- 


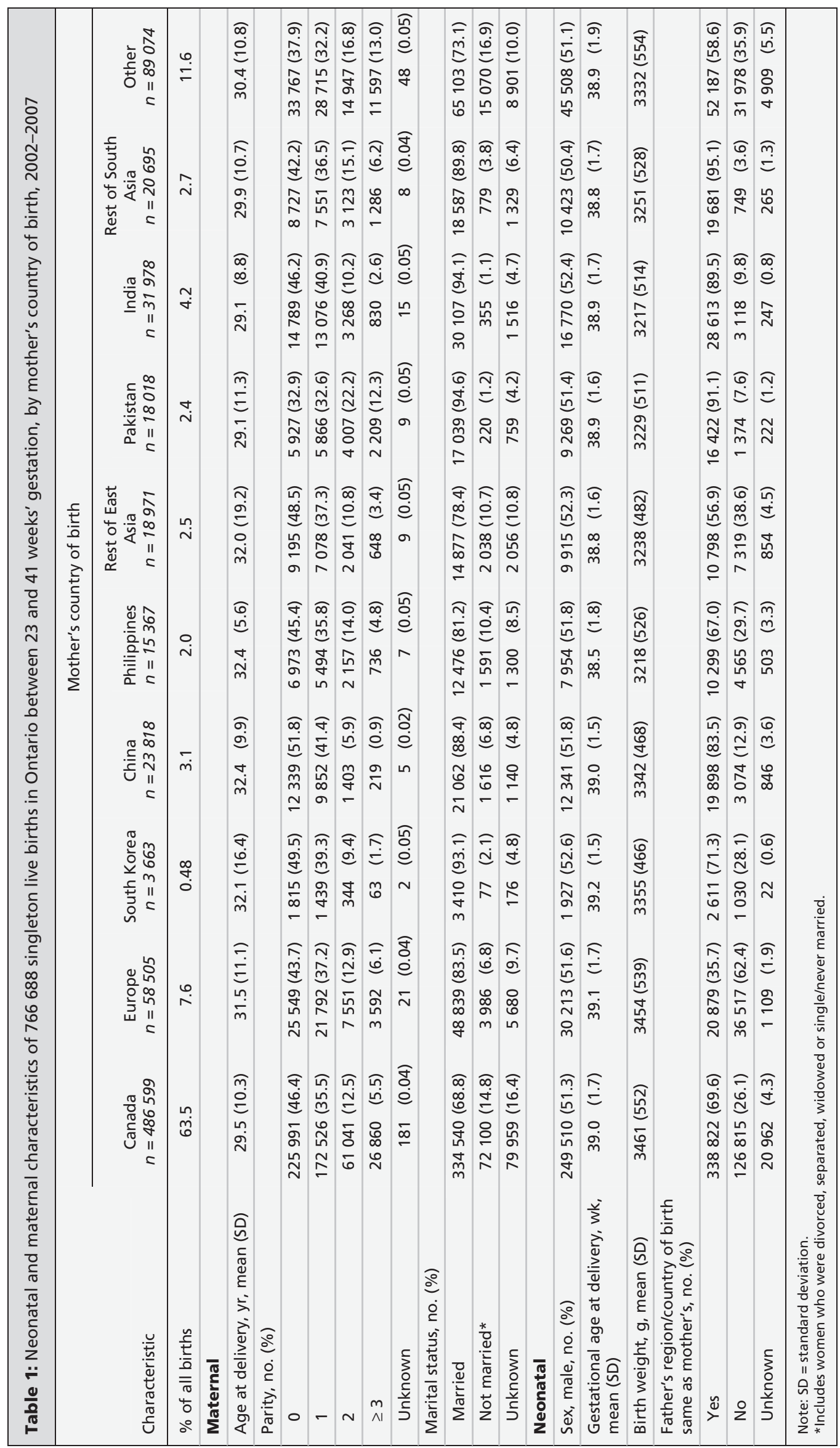


male was higher, especially among immigrants from India (1.90). A limitation of census-based studies, however, is that not all of the population at risk is sampled, information on live births is not detailed, and only current household members are identified, such that a deceased infant might no longer be accounted for.

The aforementioned studies concluded that female fetuses were more likely than male fetuses to be selectively terminated. ${ }^{3,6}$ However, neither of the studies, nor ours, had actual information about prior (or subsequent) terminations of pregnancies. Knowing that level of detail would help to explain these concerning trends better. In the absence of another plausible explanation, male selection remains the most likely reason for the higher male:female ratios. This may be a function of pregnancy termination, but it could also be due to sex-selected preimplantation of male eggs during in vitro fertilization, ${ }^{7}$ for example. Sex-

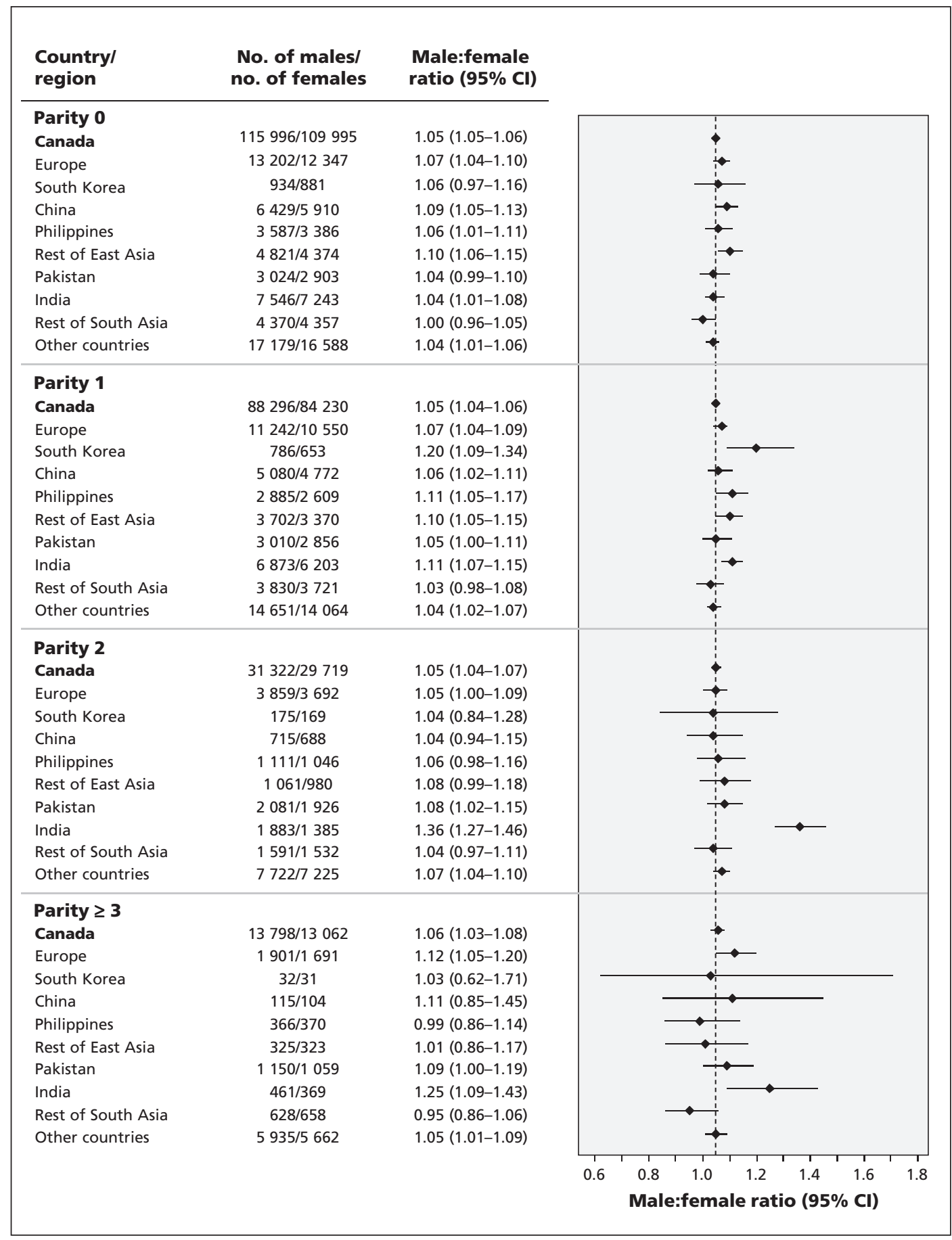

Figure 1: Male:female ratios of singleton live births in Ontario from 2002 to 2007, by mother's country of birth and stratified by maternal parity. The vertical dashed line denotes the natural sex ratio of 1.05. 
specific preimplantation might be better evaluated in a future study with the inclusion of data on multifetal pregnancies, which are more common with assisted reproductive technology.

An interesting finding in our study was the difference in the male:female ratios between parous women born in India and those born in Pakistan. Although they are neighbouring countries, India is a secular state, whereas Pakistan is an Islamic state in which abortion is religiously prohibited. ${ }^{6,89}$

\section{Limitations}

Our study has limitations. First, we included only singleton live births. Multifetal pregnancies may arise following assisted reproduction, wherein early fetal sex selection is made more possible. By excluding multifetal pregnancies from our study, we cannot account for sex selection in this group, or its association with maternal country of birth.

Second, changes in fees to register live births in Ontario in the 1990s left a small (1\%) proportion of births unregistered, especially among poorer young mothers living in urban areas. ${ }^{10}$ The effect on our results should be minimal, however, since our study was based on $99 \%$ of live births.

Third, the dataset we used did not indicate when women born outside of Canada immigrated to Canada, nor did it give the ethnic backgrounds of the Canadian-born women. Because most Canadian-born women in our study were born 25-35 years ago, we might surmise that most were of European ancestry, the predominant ethnic group in that era. ${ }^{11}$

Fourth, our data describe live births in Ontario, which may differ from births in other parts of Canada, including the composition of immigrants.

Finally, although more than one birth for a given woman may have been included in the study, we were unable to link siblings or determine the sex of a prior sibling born to the same woman.

\section{Conclusion}

Our study of male:female ratios in Ontario showed that multiparous women born in India were significantly more likely than multiparous women born in Canada to have a male infant.
Whether this difference in sex ratios was the result of prenatal sex selection should be determined by direct study of practices of sexselected preimplantation and pregnancy termination among individuals from various world regions. In addition, an analysis of the duration of residence in Canada, access to fertility care, family income and parental preferences would be of value in describing factors that might influence prenatal sex selection.

\section{References}

1. Ostler S, Sun A. Fetal sex determination: the predictive value of 3 common myths. CMAJ 1999;161:1525-6.

2. Odeh M, Granin V, Kais M, et al. Sonographic fetal sex determination. Obstet Gynecol Surv 2009;64:50-7.

3. Jha P, Kesler MA, Kumar R, et al. Trends in selective abortions of girls in India: analysis of nationally representative birth histories from 1990 to 2005 and census data from 1991 to 2011. Lancet 2011;377:1921-8.

4. Kale R. "It's a girl!"- - could be a death sentence. CMAJ 2012;184 387-8.

5. Vogel L. Sex selection migrates to Canada. CMAJ 2012;184: E163-4.

6. Almond D, Edlund L, Milligan KO. O sister, where art thou? The role of son preference and sex choice: evidence from immigrants to Canada [NBER working paper no. 15391]. Cambridge (MA): National Bureau of Economic Research; 2009, revised Oct. 2010.

7. Sills ES, Palermo GD. Preimplantation genetic diagnosis for elective sex selection, the IVF market economy, and the child Another long day's journey into night? J Assist Reprod Genet 2002; 19:433-7.

8. Vlassoff M, Singh S, Suarez G, et al. Abortion in Pakistan. In Brief. New York (NY): Guttmacher Institute; 2009, no. 2. Available: www.guttmacher.org/pubs/IB_Abortion-in-Pakistan.pdf (accessed 2011 Mar. 20)

9. Rahman A, Katzive L, Henshaw SK. A global review of laws on induced abortion, 1985-1997. Int Fam Plan Perspect 1988;24: 56-64.

10. Woodward GL, Bienefeld MK, Ardal S. Under-reporting of live births in Ontario: 1991-1997. Can J Public Health 2003;94:463-7.

11. Anderson AB, Frideres JS. Ethnicity in Canada: theoretical perspectives. Toronto (ON): Butterworth; 1981.

Affiliations: From the Departments of Medicine, Health Policy Management and Evaluation, and Obstetrics and Gynecology (Ray), St. Michael's Hospital and University of Toronto; the Institute for Clinical Evaluative Sciences (Ray, Henry, Urquia); the Department of Medicine (Henry), University of Toronto; and the Centre for Research on Inner City Health (Urquia), St. Michael's Hospital, Toronto, Ont.

Contributors: Joel Ray and Marcelo Urquia contributed to the study conception and design, the analysis of the data, and the drafting and critical revision of the manuscript. David Henry contributed to the analysis and interpretation of the data and the critical revision of the manuscript. All of the authors approved the final version of the manuscript submitted for publication.

Funding: No funding was received for this study.

Acknowledgement: Dr. Rick Glazier provided helpful comments on a draft of the manuscript. 